\title{
Response of Aspergillus niger Inoculated on Tomatoes Exposed to Vapor Phase Mustard Essential Oil for Short or Long Periods and Sensory Evaluation of Treated Tomatoes
}

\author{
Ana Elena Aguilar-González, Enrique Palou, and Aurelio López-Malo \\ Departamento de Ingeniería Química y Alimentos, Universidad de las Américas Puebla, 72810 San Andrés Cholula, PUE, Mexico \\ Correspondence should be addressed to Aurelio López-Malo; aurelio.lopezm@udlap.mx
}

Received 13 October 2017; Revised 6 December 2017; Accepted 12 December 2017; Published 27 December 2017

Academic Editor: Ángel A. Carbonell-Barrachina

Copyright @ 2017 Ana Elena Aguilar-González et al. This is an open access article distributed under the Creative Commons Attribution License, which permits unrestricted use, distribution, and reproduction in any medium, provided the original work is properly cited.

\begin{abstract}
The inhibitory effect of mustard essential oil (EO) in vapor phase against Aspergillus niger was evaluated in vitro and in vivo (in tomatoes). Mold response in tomatoes exposed for short or long periods to selected concentrations of mustard EO was also evaluated. Furthermore, a sensory evaluation was also performed among treated tomatoes and compared with nontreated ones. Minimum inhibitory concentration (MIC) for the studied EO was determined by the inverted Petri dish method. MIC for the in vitro and in vivo tests for mustard $\mathrm{EO}$ was of $3.08 \mu \mathrm{L} / \mathrm{L}_{\text {air }}$. In vitro and in vivo results demonstrate the effectiveness of vapors of mustard EO against $A$. niger. The studied EO contains highly volatile organic compounds with strong inhibitory effects, even when applied for short periods, and can consequently be considered a good alternative to traditional synthetic antimicrobials without detriment of selected sensory attributes.
\end{abstract}

\section{Introduction}

Tomato (Solanum lycopersicum L.) is one of the most cultivated fruits worldwide; according to the Food and Agriculture Organization (FAO) of the United Nations, from 2012 to 2013 nearly 162 million tons of tomatoes were produced worldwide, with China being the largest producer (just over 50 million tons during this period). Mexico produced $3,433,567$ million tons representing a yield of $355,254 \mathrm{~kg} / \mathrm{ha}$, placing it in the top 10 leading producers of this fruit and as the top exporter $[1,2]$. However, tomato is extremely susceptible to various diseases caused by biological agents such as fungi, bacteria, and viruses, causing huge production and economic losses, which in some cases can amount to up to half of the production [3]. Aspergillus niger is a highly pathogenic fungi of plants since it is able to colonize through wounds or natural openings of the plant tissue, thereby deteriorating corresponding produce. A. niger has been reported as a major cause of infections in many perishable products, including tomatoes, during harvest, storage, and transportation [4, 5]. Ruiz-Martínez et al. [2] developed various methods to prevent or retard deterioration of tomato fruits, which include the use of low temperatures, edible coatings, controlled atmospheres, and chemical treatments. However, nowadays consumers prefer products with less or no synthetic additives; consequently, the search for new preservation alternatives is an area of broad interest to the food industry [6-9]. The use of essential oils (EOs) from plants as natural antimicrobial agents has increased in recent years, due to multiple reports demonstrating that many of these EOs have antifungal, antimicrobial, and/or insecticidal activities [10-14]. In particular, mustard essential oil has been thoroughly studied given its effective antimicrobial effect at relatively low concentrations [15-20]. Mustard EO or its major component, allyl isothiocyanate, has been incorporated in edible films or encapsulated in different matrices with reasonable antibacterial and antifungal effects $[15,19]$; however, these same authors also mentioned that their application to food products is still limited due to their high volatility and strong odors $[15,16,19,20]$. Different strategies 
have been tested to diminish the odor effect on foods when using mustard EO, such as its controlled release by means of encapsulation [19]. Another approach could be the exposure of foods to mustard EO in vapor phase for selected periods of time $[16,20]$. Thus, in this study the antifungal effect of the EO of mustard (Brassica nigra) in vapor phase was evaluated; in addition, inoculated tomatoes were used as a biological model to evaluate the inhibitory effect of studied EO when exposed for short or long periods as well as the impact of selected treatments on sensory attributes of treated tomatoes compared with nontreated ones.

\section{Materials and Methods}

2.1. Essential Oil. Mustard EO was purchased from Grupo Tecnaal (Aromáticos Químicos Potosinos, SA de CV, Mexico); the oil was kept in amber-flasks under refrigerated $\left(4^{\circ} \mathrm{C}\right)$ conditions until use. Mustard EO was analyzed as previously described by Aguilar-González et al. [20] by gas chromatography coupled to mass spectrometry (GC-MS). The identification of its major compounds was performed by comparison with the database of the National Institute of Standards and Technology.

2.2. Antifungal Assays. A. niger (ATCC 1015) was obtained from the culture collection of the Food Microbiology Laboratory at Universidad de las Américas Puebla. Sterilized potatodextrose agar (PDA) slants (Bioxon, Becton-Dickinson and Company, USA) were prepared according to the manufacturer's instructions to maintain studied mold culture for $10 \mathrm{~d}$ at $25^{\circ} \mathrm{C}$ (Lab Line, Inc., Melrose Park, IL, USA). Spores were harvested by washing the surface of the slants with $10 \mathrm{~mL}$ of sterile water and adjusting the suspensions to $10^{6}$ spores $/ \mathrm{mL}$ using a hemocytometer [21].

\subsection{In Vitro Tests: Minimum Inhibitory Concentration Deter-} mination. Minimum inhibitory concentration (MIC) of mustard EO was determined by the inverted Petri dish method as reported by Yun et al. [22] and Aguilar-González et al. [20], pouring $0.0,0.1,0.2,0.3,0.4,0.5,0.6,0.7,0.8$, 0.9 , or $1.0 \mu \mathrm{L}$ of essential oil (using a $0.1-1.0 \mu \mathrm{L}$ microEppendorf pipette) in sterilized Whatman ${ }^{\circledR}$ No. 1 filter paper $(6.0 \mathrm{~mm})$ placed in the center of the dish lid. PDA plates $(60$ $\times 15 \mathrm{~mm}$ ) were inoculated in the center with $5 \mu \mathrm{L}$ of spore suspension, sealed with Parafilm ${ }^{\circledR}$, and incubated at $27 \pm 1^{\circ} \mathrm{C}$. Mold colony diameter was measured daily for up to 10 days with a Vernier caliper. Every experiment was performed in triplicate.

2.4. In Vivo Tests: Determination of Vapor Phase Antifungal Activity of EO in Inoculated Tomatoes. Ripe tomatoes (Solanum lycopersicum L. Saladette cultivar) were purchased in a local market (Cholula, Puebla, Mexico). The fruit was used the same day of purchase to prevent deterioration during storage or manipulation. They were disinfected with a $10 \mathrm{~mL} / \mathrm{L} \mathrm{NaClO}$ solution for $10 \mathrm{~min}$ and then washed with sterile water and allowed to dry at room temperature for $10 \mathrm{~min}$.
Each tomato was inoculated using the needle of a $5 \mathrm{~mL}$ syringe to open a wound of $1 \mathrm{~mm}$ depth at four points around the stem and placing an aliquot of $5 \mu \mathrm{L}$ of the $A$. niger spore suspension in each wound. Then, every tomato was placed in a $1.85 \mathrm{~L}$ hermetic seal transparent plastic container. A piece of $40 \mathrm{~mm}^{2}$ of Whatman No. 1 filter paper was taped to the upper side of the inner-wall of the containers where the MIC of the EO was poured (tested concentrations were adjusted to the volume of the $1.85 \mathrm{~L}$ containers). Inoculated tomatoes, without EO in the containers, served as controls. The containers were closed, placed upside down, and sealed with Parafilm to prevent vapors from leaking. The inoculated tomatoes were incubated for $10 \mathrm{~d}$ at room temperature and protected from light, and mold growth was monitored daily. Every experiment was performed 5 times.

\subsection{Antifungal Activity of Mustard Essential Oil in Vapor} Phase on Inoculated Tomatoes Treated for Short Periods of Time. Since mustard EO had been previously reported to be extremely effective in preventing mold growth [8, 23-26], selected additional experiments were conducted: inoculated tomatoes were prepared as described before and the previously determined MIC was used to evaluate the efficacy of mustard EO in vapor phase when applied for short periods of time. In the first experiment, MIC, double MIC (2M), and triple MIC (3M) of mustard essential oil were poured on the filter paper, placed in the plastic containers, sealed with Parafilm, and exposed for 1, 2, 4, or $24 \mathrm{~h}$; after these treatments, the tomatoes were placed in clean and sealed containers without EO. For the second experiment, inoculated tomatoes where exposed to the MIC, (3/4)MIC $((3 / 4) \mathrm{M})$, half of the MIC $((1 / 2) \mathrm{M})$, and $(1 / 4) \mathrm{MIC}((1 / 4) \mathrm{M})$ of mustard EO for $30 \mathrm{~min}, 45 \mathrm{~min}, 1 \mathrm{~h}$, or $24 \mathrm{~h}$ as mentioned above, and then the tomatoes were also placed in clean and sealed containers without EO.

In both experiments, incubation after treatments was allocated for $10 \mathrm{~d}$ at $25^{\circ} \mathrm{C}$, monitoring mold growth daily. The number of inoculated wounds with mold growth was recorded for every tested experimental condition; which was performed 5 times.

2.6. Sensory Evaluation. Tomatoes exposed to mustard EO for short periods of time were subjected to sensory evaluation; these tomatoes were prepared according to the methodology described above, but without fungal inoculation. After corresponding treatment, each tomato was cut in $2 \mathrm{~cm}$ pieces, to ensure a proper amount of peel and pulp in each piece for sensory analysis. Assessed treatments were $\mathrm{M}$ for $30 \mathrm{~min}$, $(3 / 4) \mathrm{M}$ for $24 \mathrm{~h}$, and $(1 / 2) \mathrm{M}$ for $24 \mathrm{~h}$. Every treated tomato was sensory evaluated right after the period of time of the treatment was finished (day 0) and two days after their exposure to studied EO in order to compare the effect of time in the assessed attributes. Twenty-five untrained judges evaluated odor, flavor, and overall acceptability. A 9-point hedonic scale was used to evaluate studied samples in which a score of 1 represents the attribute most disliked and a score of 9 represents the attribute most liked. Scores around 6 were considered acceptable; furthermore, comments from judges regarding the assessed products were encouraged. 
TABLE 1: Aspergillus niger colony diameter after $10 \mathrm{~d}$ of incubation in the presence of mustard essential oil (inverted Petri dish technique).

\begin{tabular}{lcc}
\hline $\begin{array}{l}\text { Essential oil volume } \\
(\mu \mathrm{L})\end{array}$ & $\begin{array}{c}\text { Essential oil } \\
\text { concentration }\left(\mu \mathrm{L} / \mathrm{L}_{\mathrm{air}}\right)\end{array}$ & $\begin{array}{c}\text { Colony diameter } \\
(\mathrm{mm})\end{array}$ \\
\hline 0.0 & 0.00 & $43 \pm 2$ \\
0.1 & 3.08 & 0 \\
0.2 & 6.17 & 0 \\
0.3 & 9.26 & 0 \\
0.4 & 12.34 & 0 \\
0.5 & 15.43 & 0 \\
$\ldots$ & $\ldots$ & $\ldots$ \\
1.0 & 30.86 & 0 \\
\hline
\end{tabular}

2.7. Statistical Analysis. The effects of tested EO evaluated in this work were determined by ANOVA and Tukey test $(p<$ 0.05) using Minitab 16 software (Minitab, Inc., State College, PA, USA).

\section{Results and Discussion}

Chemical analysis results for mustard EO were similar to those previously reported by Aguilar-González et al. [20]. Identified compounds of studied mustard EO show that its major component was allyl isothiocyanate (AITC) present in a proportion of 98.4 percent. These results are also comparable with previous reports by Suhr and Nielsen [25] and Lin et al. [27].

\subsection{Determination of In Vitro MIC of Mustard EO. Table 1} presents $A$. niger average colony diameters obtained during MIC tests for vapor phase mustard EO. It can be observed that the lowest volume tested $(0.1 \mu \mathrm{L})$ was enough to inhibit fungal growth, so the concentration of EO that resulted in total absence of mold growth after $10 \mathrm{~d}$ of incubation and defined as MIC was $3.08 \mu \mathrm{L}$ mustard $\mathrm{EO} / \mathrm{L}_{\mathrm{air}}$, similar to the results reported by Aguilar-González et al. [20] where mustard EO inhibited Botrytis cinerea. Tullio et al. [28] reported volumes of 78-156 $\mu \mathrm{L} / \mathrm{L}_{\text {air }}$ for thyme EO, $5000-10000 \mu \mathrm{L} / \mathrm{L}_{\text {air }}$ for fennel $\mathrm{EO}$, and $156-312 \mu \mathrm{L} / \mathrm{L}_{\text {air }}$ for lemon balm as MICs for A. niger when applied by vapor contact; the MIC obtained in our case $\left(3.08 \mu \mathrm{L} / \mathrm{L}_{\text {air }}\right)$ is much lower.

On the other hand, Wu et al. [26] reported an in vitro $\mathrm{EC}_{95}$ (effective concentration that inhibits $95 \%$ of the spore population) of $1.43 \mathrm{~g} / \mathrm{L}$ for AITC (principal compound of studied mustard EO and mainly responsible for its inhibitory effect) in vapor phase against Penicillium expansum and $0.69 \mathrm{~g} / \mathrm{L}$ against $B$. cinerea after $7 \mathrm{~d}$ of continuous flow treatment, which are slightly lower concentrations compared to the ones obtained in our case, probably due to the controlled atmosphere tested by them and/or to a higher sensitivity of their studied molds.

3.2. Determination of Vapor Phase Antifungal Activity of EO in Inoculated Tomatoes. The inoculated tomatoes without exposure to vapor phase mustard EO presented growth in every inoculated wound before $10 \mathrm{~d}$. However, when testing the MIC ( $3.08 \mu \mathrm{L} / \mathrm{L}_{\text {air }}$ of mustard EO), none of the inoculated fruits/wounds presented $A$. niger growth. These findings reveal that in our case the in vitro results were confirmed during the in vivo tests. The mechanism of action of EOs is still unclear since they are complex mixtures of different constituents that have several targets on the microorganisms; therefore, it is difficult to predict the susceptibility of a particular microorganism for a specific EO. However, several studies suggest that the volatile compounds compromise the cellular metabolism when they penetrate the cell; other studies have proposed that the integrity of the mold's cell membrane gets disrupted resulting in the release of cellular content [29-31]. Inouye et al. [32] reported that EOs containing alcohols, ketones, esters, oxides, and hydrocarbons as major constituents exhibited greater inhibitory activities when applied in vapor phase compared to their application in liquid phase against several microorganisms.

\subsection{Antifungal Activity of Mustard EO in Vapor Phase} on Inoculated Tomatoes Treated for Short Periods of Time. Table 2 presents the number of wounds (inoculated with $A$. niger) on tomatoes that displayed mold growth after $10 \mathrm{~d}$ of incubation exposed to mustard EO vapors, revealing that after $10 \mathrm{~d}$ of incubation, one of the effective treatments to inhibit $A$. niger growth on inoculated tomatoes consisted in exposing them to the MIC established in this work $(3.08 \mu \mathrm{L}$ of mustard $\left.\mathrm{EO} / \mathrm{L}_{\mathrm{air}}\right)$ for $30 \mathrm{~min}$. Other treatments that were also effective include exposing the fruits to $(3 / 4) \mathrm{M}\left(2.31 \mu \mathrm{L} / \mathrm{L}_{\text {air }}\right)$ or $(1 / 2) \mathrm{M}\left(1.54 \mu \mathrm{L} / \mathrm{L}_{\text {air }}\right)$ for $24 \mathrm{~h}$. On the other hand, $A$. niger growth began at day 4 of incubation in the case of tomatoes being exposed to $(1 / 4) \mathrm{M}\left(0.77 \mu \mathrm{L} / \mathrm{L}_{\text {air }}\right)$; for other volumes tested, mold growth began until day 6 of incubation, while for volumes higher than the MIC ( $2 \mathrm{M}$ and $3 \mathrm{M})$ the mold did not grow, as expected. Moreover, "control" inoculated tomatoes presented growth, as anticipated. Although in this experiment $A$. niger grew on most of the inoculated tomatoes, there was a delay on its growth generated by exposure to the mustard EO vapors while total inhibition was also observed in selected cases, depending on the volume of mustard EO and time of exposure to the volatile compounds generated by its vapors. Mari et al. [8] performed a similar study in which they evaluated AITC vapors against $P$. expansum inoculated on pears; their results showed that the best treatment was obtained by exposing pears for $24 \mathrm{~h}$ in a $5 \mathrm{~g} / \mathrm{L}$ AITC-enriched atmosphere (in a continuous flow, i.e., a controlled atmosphere); in our case, lower concentrations of mustard EO were needed for the same period of time; this could be due to the difference in the $\mathrm{pH}$ of each fruit and/or to different mold sensitivities. On the other hand, Wu et al. [26] tested AITC in vapor phase on apples inoculated with $P$. expansum and $B$. cinerea, reporting an $\mathrm{EC}_{95}$ of $1.43 \mathrm{~g} / \mathrm{L}$ for $P$. expansum and of $0.69 \mathrm{~g} / \mathrm{L}$ for $B$. cinerea as well as for their in vitro results; these concentrations are lower than the ones obtained in our case. Nevertheless, the length of their in vivo treatment was $4 \mathrm{~d}$ (in a continuous flow), so this might contribute to the need for less amounts of AITC to ensure a successful inhibitory effect. According to Yun et al. [22], AITC is a smaller molecule and more volatile than other compounds present 
TABLE 2: Number of wounds (inoculated with Aspergillus niger) on tomatoes that presented mold growth after $10 \mathrm{~d}$ of incubation with mustard essential oil in vapor phase at selected concentrations and periods of time.

\begin{tabular}{|c|c|c|}
\hline Essential oil volume & Exposure time & Number of wounds with mold growth \\
\hline \multirow{4}{*}{$3 \mathrm{M}\left(9.26 \mu \mathrm{L} / \mathrm{L}_{\text {air }}\right)$} & $24 \mathrm{~h}$ & $0 / 20$ \\
\hline & $4 \mathrm{~h}$ & $0 / 20$ \\
\hline & $2 \mathrm{~h}$ & $0 / 20$ \\
\hline & $1 \mathrm{~h}$ & $0 / 20$ \\
\hline \multirow{4}{*}{$2 \mathrm{M}\left(6.17 \mu \mathrm{L} / \mathrm{L}_{\text {air }}\right)$} & $24 \mathrm{~h}$ & $0 / 20$ \\
\hline & $4 \mathrm{~h}$ & $0 / 20$ \\
\hline & $2 \mathrm{~h}$ & $0 / 20$ \\
\hline & $1 \mathrm{~h}$ & $0 / 20$ \\
\hline \multirow{6}{*}{$\mathrm{M}\left(3.08 \mu \mathrm{L} / \mathrm{L}_{\mathrm{air}}\right)$} & $24 \mathrm{~h}$ & $0 / 20$ \\
\hline & $4 \mathrm{~h}$ & $0 / 20$ \\
\hline & $2 \mathrm{~h}$ & $0 / 20$ \\
\hline & $1 \mathrm{~h}$ & $0 / 20$ \\
\hline & $45 \mathrm{~min}$ & $0 / 20$ \\
\hline & $30 \mathrm{~min}$ & $0 / 20$ \\
\hline \multirow{4}{*}{$(3 / 4) \mathrm{M}\left(2.31 \mu \mathrm{L} / \mathrm{L}_{\mathrm{air}}\right)$} & $24 \mathrm{~h}$ & $0 / 20$ \\
\hline & $1 \mathrm{~h}$ & $8 / 20$ \\
\hline & $45 \mathrm{~min}$ & $10 / 20$ \\
\hline & $30 \mathrm{~min}$ & $12 / 20$ \\
\hline \multirow{4}{*}{$(1 / 2) \mathrm{M}\left(1.54 \mu \mathrm{L} / \mathrm{L}_{\text {air }}\right)$} & $24 \mathrm{~h}$ & $0 / 20$ \\
\hline & $1 \mathrm{~h}$ & $10 / 20$ \\
\hline & $45 \mathrm{~min}$ & $12 / 20$ \\
\hline & $30 \mathrm{~min}$ & $13 / 20$ \\
\hline \multirow{4}{*}{$(1 / 4) \mathrm{M}\left(0.77 \mu \mathrm{L} / \mathrm{L}_{\text {air }}\right)$} & $24 \mathrm{~h}$ & $20 / 20$ \\
\hline & $1 \mathrm{~h}$ & $20 / 20$ \\
\hline & $45 \mathrm{~min}$ & $20 / 20$ \\
\hline & $30 \mathrm{~min}$ & $20 / 20$ \\
\hline \multirow{6}{*}{$0 \mathrm{M}\left(0.00 \mu \mathrm{L} / \mathrm{L}_{\mathrm{air}}\right)$} & $24 \mathrm{~h}$ & $20 / 20$ \\
\hline & $4 \mathrm{~h}$ & $20 / 20$ \\
\hline & $2 \mathrm{~h}$ & $20 / 20$ \\
\hline & $1 \mathrm{~h}$ & $20 / 20$ \\
\hline & $45 \mathrm{~min}$ & $20 / 20$ \\
\hline & $30 \mathrm{~min}$ & $20 / 20$ \\
\hline
\end{tabular}

in several EOs, such as carvacrol and cinnamaldehyde; thus, this is probably one of the reasons of the extraordinary effectiveness of mustard EOs. Wu et al. [19] reported that microcapsules containing AITC could effectively regulate release of this compound, decreasing its strong/irritant odor and nonetheless maintaining its antimicrobial action when applied to green tomatoes; these authors reported that the storage time of the microcapsule-AITC treated tomato was prolonged and the sensory quality of treated tomatoes was better than the control (nontreated) tomatoes.

3.4. Sensory Evaluation. Table 3 presents sensory results obtained for the vapor phase mustard EO treated tomatoes for $30 \mathrm{~min}$ with the MIC of this EO. Statistical analyses indicate that there were no significant differences $(p>$ $0.05)$ in the evaluated attributes between samples; however, odor difference was detected when comparing samples from different days. Panelists were not informed about the tested vapor phase mustard EO treatment; only three panelists detected a "garlic" flavor while two reported a "spicy" flavor for the M30 tomatoes at day zero, but none of them reported any similar comments on the second day of evaluation for any of the tomatoes.

Table 3 also presents sensory results obtained for the vapor phase mustard EO treated tomatoes with (3/4)MIC or $(1 / 2)$ MIC for $24 \mathrm{~h}$. Statistical analysis revealed that there were no significant differences $(p>0.05)$ on the evaluated attributes when comparing samples from the same day; however, there was a difference in flavor and overall acceptability when comparing samples from different days. In this case, only one panelist reported an "onion" flavor on the second day of evaluation for tomatoes exposed to (3/4)M for $24 \mathrm{~h}$. 
TABLE 3: Sensory evaluation results (mean \pm standard deviation) obtained for tomatoes treated with the minimal inhibitory concentration (MIC) of mustard essential oil $\left(3.08 \mu \mathrm{L} / \mathrm{L}_{\text {air }}\right)$ for $30 \mathrm{~min}(\mathrm{M} 30)$ or selected MIC proportions $((3 / 4) \mathrm{M}$ or $(1 / 2) \mathrm{M})$ of mustard essential oil for $24 \mathrm{~h}$.

\begin{tabular}{lcccc}
\hline & Sample & Odor & Flavor & Overall acceptability \\
\hline \multirow{2}{*}{ Day 0 } & M30 & $6.08 \pm 1.46^{\mathrm{A}, \mathrm{b}}$ & $6.63 \pm 1.44^{\mathrm{A}, \mathrm{a}}$ & $6.63 \pm 1.39^{\mathrm{A}, \mathrm{a}}$ \\
& Control & $6.80 \pm 1.24^{\mathrm{A}, \mathrm{a}}$ & $6.45 \pm 2.03^{\mathrm{A}, \mathrm{a}}$ & $6.45 \pm 1.57^{\mathrm{A}, \mathrm{a}}$ \\
\hline \multirow{2}{*}{ Day 2 } & M30 & $6.88 \pm 1.57^{\mathrm{X}, \mathrm{a}}$ & $6.90 \pm 1.65^{\mathrm{A}, \mathrm{a}}$ & $6.68 \pm 1.72^{\mathrm{A}, \mathrm{a}}$ \\
& Control & $7.15 \pm 1.38^{\mathrm{X}, \mathrm{a}}$ & $6.50 \pm 2.01^{\mathrm{A}, \mathrm{a}}$ & $6.50 \pm 1.93^{\mathrm{A}, \mathrm{a}}$ \\
\hline \multirow{2}{*}{ Day 0 } & $(3 / 4) \mathrm{M} 24 \mathrm{~h}$ & $6.90 \pm 1.85^{\mathrm{A}, \mathrm{a}}$ & $6.60 \pm 1.53^{\mathrm{A}, \mathrm{a}}$ & $6.90 \pm 1.65^{\mathrm{A}, \mathrm{a}}$ \\
& $(1 / 2) \mathrm{M} 24 \mathrm{~h}$ & $6.55 \pm 1.73^{\mathrm{A}, \mathrm{a}}$ & $6.10 \pm 2.10^{\mathrm{A}, \mathrm{a}}$ & $5.85 \pm 2.45^{\mathrm{A}, \mathrm{a}}$ \\
\hline \multirow{3}{*}{ Day 2 } & Control & $6.60 \pm 1.69^{\mathrm{A}, \mathrm{a}}$ & $6.15 \pm 2.05^{\mathrm{A}, \mathrm{a}}$ & $6.15 \pm 1.87^{\mathrm{A}, \mathrm{a}}$ \\
& $(3 / 4) \mathrm{M} 24 \mathrm{~h}$ & $6.15 \pm 1.81^{\mathrm{A}, \mathrm{a}}$ & $5.40 \pm 1.93^{\mathrm{A}, \mathrm{b}}$ & $5.65 \pm 1.92^{\mathrm{A}, \mathrm{b}}$ \\
& $(1 / 2) \mathrm{M} 24 \mathrm{~h}$ & $6.00 \pm 1.74^{\mathrm{A}, \mathrm{a}}$ & $6.00 \pm 1.95^{\mathrm{A}, \mathrm{a}}$ & $6.10 \pm 1.51^{\mathrm{A}, \mathrm{a}}$ \\
\hline
\end{tabular}

Means followed by the same letter are not significantly different $(p>0.05)$ between samples evaluated in the same day (capital letters) or for the same sample evaluated in different days (lowercase letters).

Selected comments regarding sensory evaluated tomatoes include the following: "There was a light garlic flavor"; "the texture of the samples were characteristic of tomato"; "natural tomato flavor"; "I can detect a spicy flavor"; "not good scent but excellent flavor"; "I really liked it." According to Goñi et al. [33] one of the advantages of using EOs in vapor phase is that their components that disperse through the atmosphere tend not to greatly affect the organoleptic properties of the foods treated with these EOs; however, organoleptic tainting seems to depend on EO vapor concentration, time of exposure, and days elapsed after treatment as evident in the work of Tzortzakis [34], where the sweetness of "cherry" tomatoes was reduced when exposed to eucalyptus and cinnamon $\mathrm{EO}$ vapors for $8 \mathrm{~h}$ at $20^{\circ} \mathrm{C}$ and 3 to $5 \mathrm{~d}$ afterwards at $13^{\circ} \mathrm{C}$. Huang et al. [35] evaluated the effect of AITC, hydrogen peroxide, acetic acid, and lactic acid on the sensory quality of spinach leaves; in this case, aerosolized treatments did not affect the sensory quality of the spinach after $10 \mathrm{~d}$ of storage, and they reported that the detectable smell of AITC faded during storage and was not detectable after day 5 . It is important to establish that a mustard (or similar) flavor could be considered compatible with tomato as well as other ones similar to its herbal natural flavor. Furthermore, it is possible that the use of studied EO in combination with other EOs may result in synergistic inhibitory effects in foods that are not normally associated with a spicy or herbal flavor, in concentrations that do not affect their flavor or aroma [36]. Although results regarding mustard EO might suggest that this essential oil is highly effective; active substances added to foods in great concentrations can compromise their wholesomeness as well as sensory attributes. Therefore, further studies may be necessary before practical application by the food industry.

\section{Conclusions}

Studied mustard EO in vapor phase was effective against $A$. niger, a mold widely detrimental to fruits and vegetables.
The main inhibitory activity exhibited by the studied EO can be attributed to its main identified compound, allyl isothiocyanate, preventing the development of $A$. niger infection in most of the tests performed on inoculated tomatoes, even when applied for short periods of time. Thus, it can be considered as an alternative to conventional antimicrobial synthetic chemicals utilized nowadays. Mustard EO can be employed to inhibit mold growth without affecting selected sensory attributes. Further studies are required to study the residual effect of these compounds and to establish if they could be used safely as antifungal agents in other food products.

\section{Conflicts of Interest}

The authors declare that there are no conflicts of interest.

\section{Acknowledgments}

The authors would like to thank the National Council for Science and Technology (CONACyT) of Mexico and Universidad de las Américas Puebla (UDLAP) for their financial support for this project. A. E. Aguilar-González gratefully acknowledges support for her Ph.D. studies from CONACyT and UDLAP.

\section{References}

[1] FAOSTAT, Food and Agriculture of the United Nations Statistics Division, 2014 http://faostat3.fao.org/home/E.

[2] J. Ruiz-Martínez, A. Vicente, J. C. Montañéz-Saenz, R. Rodríguez-Herrera, and C. R. Aguilar-González, "A perishable treasure in Mexico, tomato, technologies to prolong its shelflife," Investigación y Ciencia de la Universidad Autónoma de Aguascalientes, vol. 54, pp. 57-63, 2012.

[3] G. Rodríguez-Alvarado, J. García-López, and S. P. FernándezPavía, "Greenhouse grown tomato (Solanum lycopersicum) diseases in the central region of Michoacán," Revista Mexicana de Fitopatología, vol. 29, no. 1, pp. 50-60, 2011. 
[4] J. C. Frisvad and U. Thrane, "Mycotoxin production by common filamentous fungi," in Introduction to Food- and Airborne Fungi, R. A. Samson, E. S. Hoekstra, and J. C. Frisvad, Eds., pp. 321-330, Centraalbureau voor Schimmelcultures, Utrecht, The Netherlands, 7th edition, 2004.

[5] A. A. Ajayi and I. G. Olasehinde, "Studies on the $\mathrm{pH}$ and protein content of tomato (Lycopersicon esculentum Mill) fruits deteriorated by Aspergillus niger," Scientific Research and Essays, vol. 4, no. 3, pp. 185-187, 2009.

[6] M. Mari, S. Bautista-Baños, and D. Sivakumar, "Decay control in the postharvest system: role of microbial and plant volatile organic compounds," Postharvest Biology and Technology, vol. 122, pp. 70-81, 2016.

[7] M. Mari, F. Neri, and P. Bertolini, "Novel approaches to prevent and control postharvest diseases of fruits," Stewart Postharvest Review, vol. 3, no. 6, 2007.

[8] M. Mari, O. Leoni, R. Iori, and T. Cembali, "Antifungal vapourphase activity of allyl-isothiocyanate against Penicillium expansum on pears," Plant Pathology, vol. 51, no. 2, pp. 231-236, 2002.

[9] D. Sivakumar and S. Bautista-Baños, "A review on the use of essential oils for postharvest decay control and maintenance of fruit quality during storage," Crop Protection, vol. 64, pp. 27-37, 2014.

[10] R. Gyawali, S. A. Hayek, and S. A. Ibrahim, "Plant extracts as antimicrobials in food products, mechanisms of action, extraction methods, and applications," in Handbook of Natural Antimicrobials for Food Safety and Quality, pp. 49-68, Elsevier Ltd, Amsterdam, Netherlands, 2015.

[11] D. Kalemba, M. Piotrowska, and M. Matla, "Antifungal activity of essential oils in vapor phase," in Essential Oils as Natural Food Additives, Composition, Applications, Antioxidant and Antimicrobial Properties, L. Valgimigli, Ed., p. 356, Nova Science Publishers, Inc, New York, NY, USA, 2012.

[12] K. K. Kuorwel, M. J. Cran, K. Sonneveld, J. Miltz, and S. W. Bigger, "Essential oils and their principal constituents as antimicrobial agents for synthetic packaging films," Journal of Food Science, vol. 76, no. 9, pp. R164-R177, 2011.

[13] R. R. Sharma, D. Singh, and R. Singh, "Biological control of postharvest diseases of fruits and vegetables by microbial antagonists: a review," Biological Control, vol. 50, no. 3, pp. 205221, 2009.

[14] W. Feng, J. Chen, X. Zheng, and Q. Liu, "Thyme oil to control Alternaria alternata in vitro and in vivo as fumigant and contact treatments," Food Control, vol. 22, no. 1, pp. 78-81, 2011.

[15] G. Chen and B. Liu, "Cellulose sulfate based film with slowrelease antimicrobial properties prepared by incorporation of mustard essential oil and $\beta$-cyclodextrin," Food Hydrocolloids, vol. 55, pp. 100-107, 2016.

[16] B. Mejía-Garibay, E. Palou, and A. López-Malo, "Composition, diffusion, and antifungal activity of black mustard (Brassica nigra) essential oil when applied by direct addition or vapor phase contact," Journal of Food Protection, vol. 78, no. 4, pp. 843$848,2015$.

[17] U. Sitara, I. Niaz, J. Naseem, and N. Sultana, "Antifungal effect of essential oils on in vitro growth of pathogenic fungi," Pakistan Journal of Botany, vol. 40, no. 1, pp. 409-414, 2008.

[18] K. Furuya and K. Isshiki, "Effect of humidity on Allyl isothiocyanate antimicrobial activity," Nippon Shokuhin Kagaku Kogaku Kaishi, vol. 48, no. 10, pp. 738-743, 2001.

[19] H. Wu, N. Xue, C.-L. Hou, J.-T. Feng, and X. Zhang, "Microcapsule preparation of allyl isothiocyanate and its application on mature green tomato preservation," Food Chemistry, vol. 175, pp. 344-349, 2015.

[20] A. E. Aguilar-González, E. Palou, and A. López-Malo, "Antifungal activity of essential oils of clove (Syzygium aromaticum) and/or mustard (Brassica nigra) in vapor phase against gray mold (Botrytis cinerea) in strawberries," Innovative Food Science and Emerging Technologies, vol. 32, pp. 181-185, 2015.

[21] A. López-Malo, S. M. Alzamora, and A. Argaiz, "Effect of vanillin concentration, $\mathrm{pH}$ and incubation temperature on Aspergillus flavus, Aspergillus niger, Aspergillus ochraceus and Aspergillus parasiticus growth," Food Microbiology, vol. 14, no. 2, pp. 117-124, 1997.

[22] J. Yun, X. Fan, and X. Li, "Inactivation of salmonella enterica serovar typhimurium and quality maintenance of cherry tomatoes treated with gaseous essential oils," Journal of Food Science, vol. 78, no. 3, pp. M458-M464, 2013.

[23] E. V. Packiyasothy and S. Kyle, "Antimicrobial properties of some herb essential oils," Food Australia, vol. 54, no. 9, pp. 384387, 2002.

[24] J. L. Paes, L. R. A. Faroni, M. A. Martins, O. D. Dhingra, and T. A. Silva, "Diffusion and sorption of allyl isothiocyanate in the process of fumigation of maize," Revista Brasileira de Engenharia Agrícola e Ambiental, vol. 15, no. 3, pp. 296-301, 2011.

[25] K. I. Suhr and P. V. Nielsen, "Antifungal activity of essential oils evaluated by two different application techniques against rye bread spoilage fungi," Journal of Applied Microbiology, vol. 94, no. 4, pp. 665-674, 2003.

[26] H. Wu, X. Zhang, G.-A. Zhang, S.-Y. Zeng, and K.-C. Lin, "Antifungal vapour-phase activity of a combination of allyl isothiocyanate and ethyl isothiocyanate against botrytis cinerea and penicillium expansum infection on apples," Journal of Phytopathology, vol. 159, no. 6, pp. 450-455, 2011.

[27] C.-M. Lin, J. F. Preston III, and C.-I. Wei, "Antibacterial mechanism of allyl isothiocyanate," Journal of Food Protection, vol. 63, no. 6, pp. 727-734, 2000.

[28] V. Tullio, A. Nostro, N. Mandras et al., "Antifungal activity of essential oils against filamentous fungi determined by broth microdilution and vapour contact methods," Journal of Applied Microbiology, vol. 102, no. 6, pp. 1544-1550, 2007.

[29] P. J. Delaquis, K. Stanich, B. Girard, and G. Mazza, "Antimicrobial activity of individual and mixed fractions of dill, cilantro, coriander and eucalyptus essential oils," International Journal of Food Microbiology, vol. 74, no. 1-2, pp. 101-109, 2002.

[30] M. E. Guynot, A. J. Ramos, L. Setó, P. Purroy, V. Sanchis, and S. Marín, "Antifungal activity of volatile compounds generated by essential oils against fungi commonly causing deterioration of bakery products," Journal of Applied Microbiology, vol. 94, no. 5, pp. 893-899, 2003.

[31] M. Hyldgaard, T. Mygind, and R. L. Meyer, "Essential oils in food preservation: mode of action, synergies, and interactions with food matrix components," Frontiers in Microbiology, vol. 3, no. 12, pp. 1-24, 2012.

[32] S. Inouye, K. Uchida, N. Maruyama, H. Yamaguchi, and S. Abe, "A novel method to estimate the contribution of the vapor activity of essential oils in agar diffusion assay," Japanese Journal of Medical Mycology, vol. 47, no. 2, pp. 91-98, 2006.

[33] P. Goñi, P. López, C. Sánchez, R. Gómez-Lus, R. Becerril, and C. Nerín, "Antimicrobial activity in the vapour phase of a combination of cinnamon and clove essential oils," Food Chemistry, vol. 116, no. 4, pp. 982-989, 2009. 
[34] N. G. Tzortzakis, "Maintaining postharvest quality of fresh produce with volatile compounds," Innovative Food Science and Emerging Technologies, vol. 8, no. 1, pp. 111-116, 2007.

[35] Y. Huang, M. Ye, and H. Chen, "Efficacy of washing with hydrogen peroxide followed by aerosolized antimicrobials as a novel sanitizing process to inactivate Escherichia coli O157:H7 on baby spinach," International Journal of Food Microbiology, vol. 153, no. 3, pp. 306-313, 2012.

[36] S. Burt, "Essential oils: their antibacterial properties and potential applications in foods-a review," International Journal of Food Microbiology, vol. 94, no. 3, pp. 223-253, 2004. 

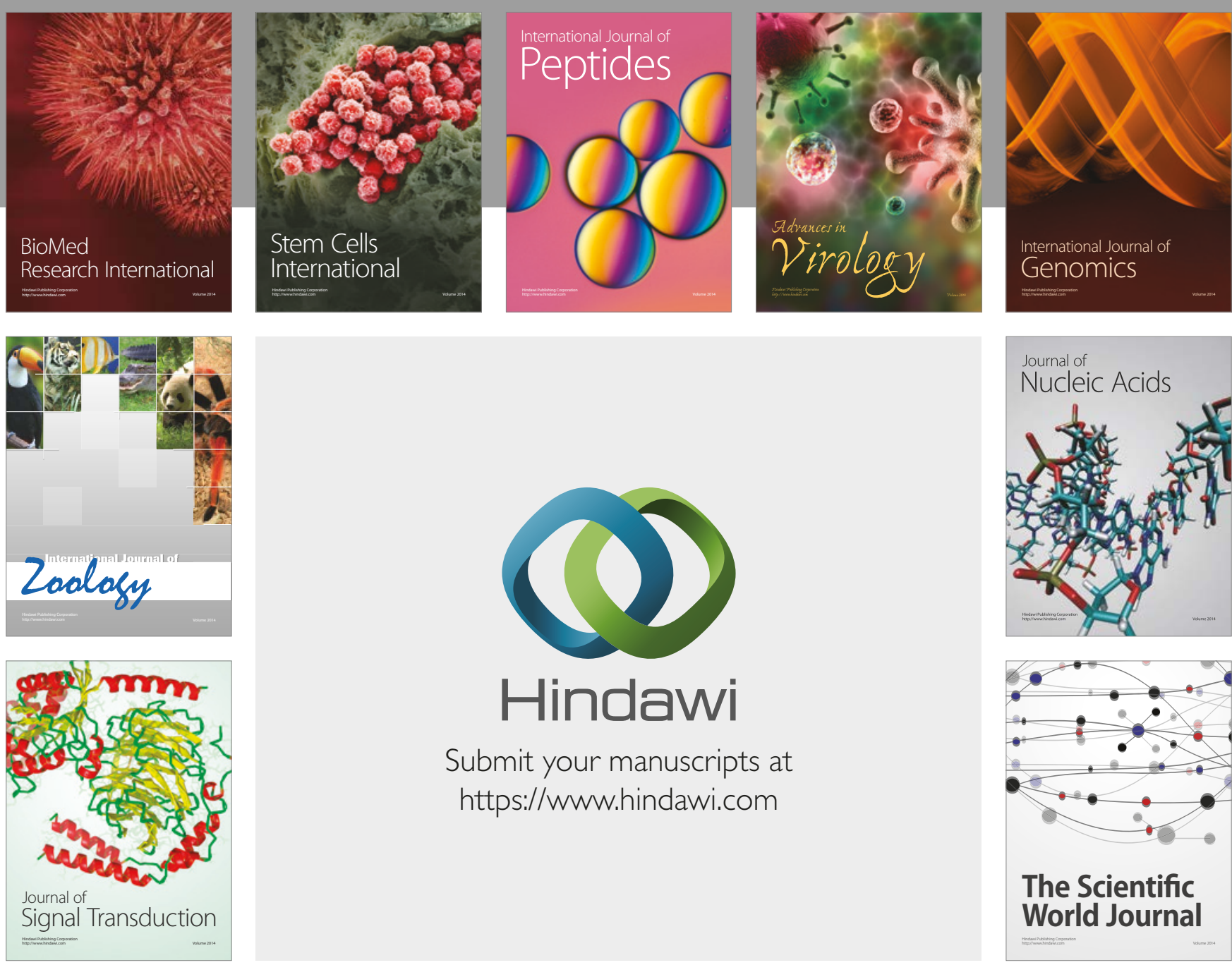

Submit your manuscripts at

https://www.hindawi.com
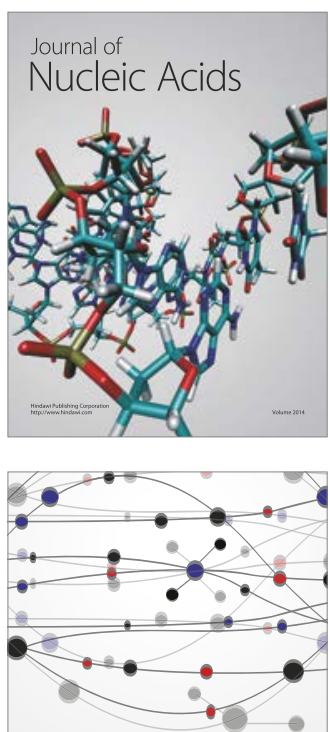

The Scientific World Journal

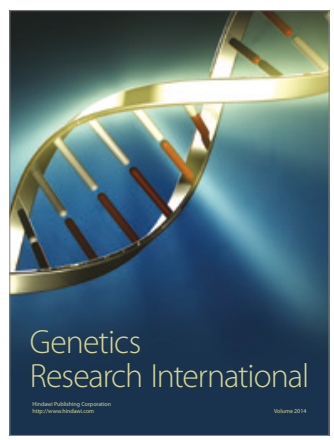

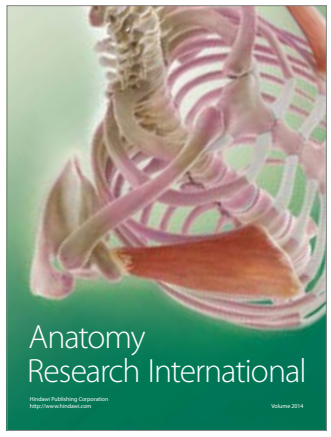

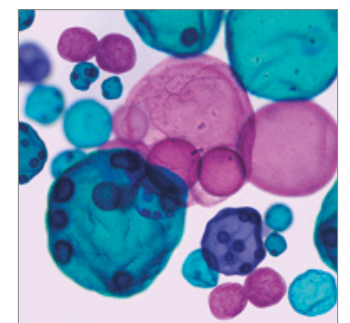

International Journal of Microbiology
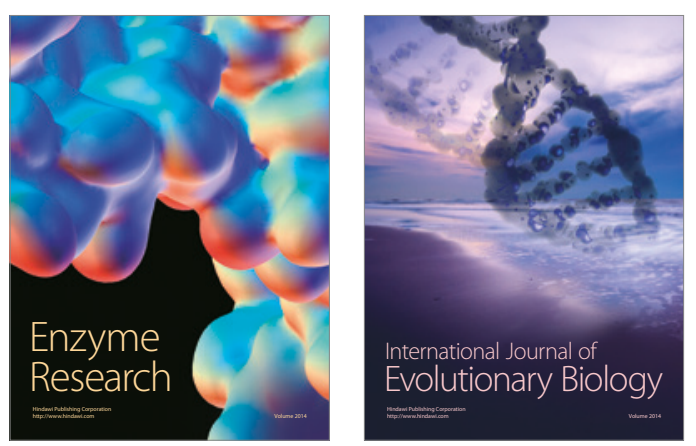
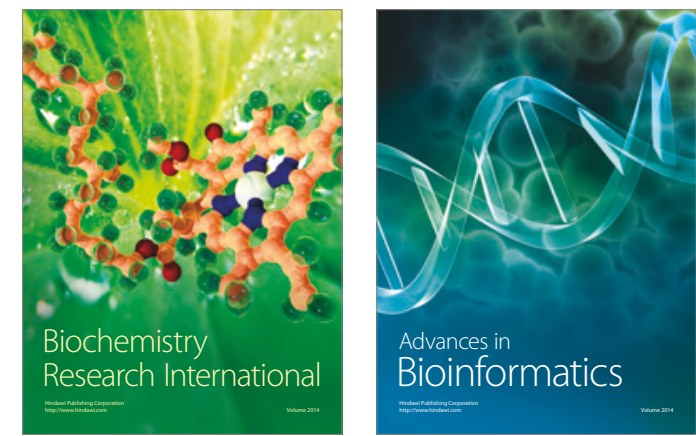

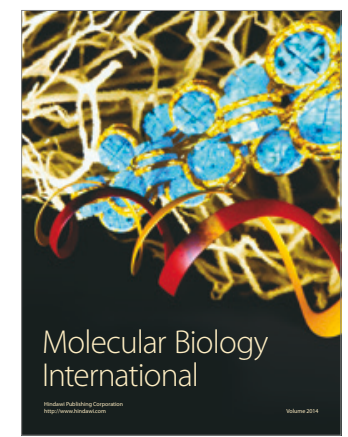

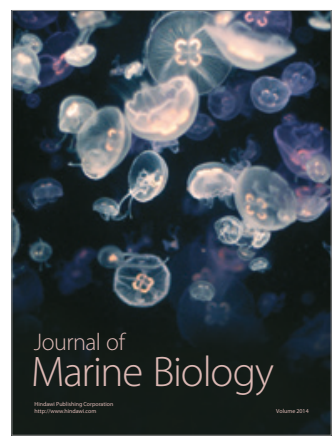

